\title{
25 Research Square \\ Physical, Perceptual, Socio-Relational and Affective Limitation of Five-Years-Old Children Born Preterm and Full-Term.
}

\section{Pedro Gil-Madrona ( $\sim$ Pedro.Gil@uclm.es )}

Universidad de Castilla-La Mancha https://orcid.org/0000-0002-1503-6394

\section{Sonia Romero-Martínez}

Universidad Nacional de Educacion a Distancia

\section{Carmen Roz-Faraco}

Universidad de Alcala de Henares

\section{Research article}

Keywords: preterm children, physical-motor skills, perceptual-motor skills, socio-relational skills

Posted Date: June 29th, 2020

DOI: https://doi.org/10.21203/rs.3.rs-37255/v1

License: (1) This work is licensed under a Creative Commons Attribution 4.0 International License. Read Full License 


\section{Abstract}

Purpose: To compare the development of physical-motor, perceptual-motor and socio-relational and affective skills of five-years-old children born preterm and full term, completing the Checklist of Psychomotor Activities.

Methods: A prospective simple ex-post facto study was conducted. The sample consisted of six hundred ninetyfour (694) five-year-old children enrolled in the third year of early childhood education in the Province of Albacete-Spain. This study is based on medical histories - prior parental written consents - and the results of evaluating the motor skills completing the Checklist of Psychomotor Activities (CPA).

Results: The study determined that children born preterm have a lower development of their physical-motor skills. In the perceptual-motor field, premature children show lower scores in the variables related to their body image and body schema, motor dissociation and visual-motor coordination, as well as in socio-relational and affective aspects. However, regarding laterality, dynamic coordination, motor execution, tonic-postural control and balance, the development of these skills is not affected.

Conclusions: The study demonstrates the needs to establish protocols oriented to the prevention of the difficulties detected in children with psychomotor high-risk and also the needs to reinforce the educational programs in this particular area to improve the integral development of children born preterm since they show less development of physical-motor perceptual-motor, socio-relational and affective skills.

\section{What's New?}

Children born preterm exhibit a lower development in variables as body image and schema, motor dissociation and coordination and, also, in socio-relational and affects. These results allow educators, pediatricians, and other professionals to develop intervention and prevention programs in this population of children.

\section{Background}

The assessment of psychomotor skills is necessary in children born preterm and full term to establish what are the physical-motor, perceptual-motor, socio-relational and affective skills that can influence in the development of the children enrolled in early childhood schools. ${ }^{1}$ For preventive reasons in preterm children, the physicalmotor aspect is one of the most important areas in their development at an early age due to its close relationship with the cognitive, emotional and affective factors of the children. ${ }^{2}$ Several authors agree that the term psychomotricity implies motor development and this in turn, implies physical changes and interaction with the context, resulting in the evolution of other processes such as cognitive and affective ones. ${ }^{3-5}$

This research evaluates the process of developing motor skills using an instrument proposed recently, the Checklist of Psychomotor Activities (CPA) ${ }^{6}$ in early ages (five-years-old) by conducting a comparative study between children born preterm and full-term and their motor and emotional skills.

When monitoring premature children the importance of the observation of their skills in the first years of life (between zero and two) is stressed despite of absence of motor deficiencies that may occur later at this age, ${ }^{7}$ it is evident the strong relationship between motor deficiencies if any, and subsequent cognitive dysfunction which supports the hypothesis that these difficulties have a common origin, ${ }^{8}$ for this reason it is important to highlight 
the importance of detection and follow up of motor and cognitive deficiencies in preterm children, ${ }^{9}$ being said deficiencies the causes of great vulnerability when they are not diagnosed. Both doctors and parent in case of preterm children consider an increase of long-term disability. In recent studies it has been determined that preterm children can maintain a disability-free survival, but the consequences that lead to socio-affective, motor and cognitive problems have not been deeply studied. ${ }^{10}$

Prematurity in children is identified as one of the causes of high biological risk detected by a multidisciplinary observation process. ${ }^{11}$ It should be noted that more than one in ten babies are born prematurely worldwide, this rate is increasing with an incidence of more than 15 million children born prematurely in the world. In addition to these alarming figures, more than one million of children die each year due to complications during preterm birth and others that survive live with disability, including learning, motor, visual and hearing problems. ${ }^{12}$

Observation and prevention of risk factors are key aspects in the identification of psycho-motor problems in premature children who may be disadvantaged compared to non-premature children; "Born preterm or having a low birthweight (LBW) is associated with significant motor deterioration that persists during childhood." ${ }^{13}$ The development of motor, perceptual, socio-relational and affective skills is a very important aspect in childhood development and it should be approached at an early age, being the basis for acquiring core subjects, aspects that support the executive functions of infants. ${ }^{14}$ The data was gathered with the most appropriate information for the study by completing a checklist developed in a previous study with observations made by teachers. ${ }^{6}$

These results highlight the importance of prevention and the establishment of referral, observation and follow-up protocols in preterm children by different areas such as medicine, education and psychology for the implementation of actions that favor children born prematurely, ${ }^{15}$ avoiding certain motor dissociations that may appear in the early years of childhood, such as those evidenced in the performance of this study; the result of the observation shows deficiencies in both body image and body schema which cause poor motor development, objective and subjective management, aspects closely related to emotional development, being these, the sources of motor sensory integration and social representations; the low scores in the visual-motor association and coordination aspects still in development in each of the learning stages, are also mentioned. ${ }^{16}$ Although many studies have assessed the motor development of premature children, only few have been conducted taking in consideration an older school age group such as the age of five-years-old, age when the initial deficiencies appear in the acquisition of core subjects and social skills, once the motor, family, cognitive, sociorelational and affective characteristics are evaluated.

The main objective of this study is to compare the psychomotor development and the socio-emotional aspects of five-year-old children taking in consideration their characteristic of born preterm and full-term. This age was chosen because it is a crucial stage between early childhood education and primary education since, it is when other psychomotor and socio-emotional skills are developed.

The hypothesis is that premature children have a lower psychomotor development than full-term children. The results of the study could allow the identification of physical-motor, perceptual-motor and socio-emotional factors influenced by the characteristic of being children born preterm or full-term, said factors would allow the design of preventive and corrective actions used by both healthcare and education professionals, aimed to promote the holistic and harmonious development of premature children, as they will start the elementary school soon, which by the way is mandatory in Spain. 


\section{Methods}

\section{METHODS.}

\section{Participants}

The data analyzed on this study belong to six hundred ninety-four children of five-years-old, enrolled in the third level of Early Childhood School, such data was gathered by teachers of 32 groups of students in 11 schools in the province of Albacete (Spain). Using a probability sampling, the children were randomly selected through the snowball sampling technique from a group of 50 schools ( 35 public and 15 semi-private) located in the province of Albacete during the year 2018 according to the city council record. ${ }^{17}$ To gather the data the consent of the parents was requested, the anonymity and confidentiality was guaranteed, and the ethical principles for medical research involving human subjects (Declaration of Helsinki) were followed. ${ }^{18}$

The sample composition is a set of girls (46.7\%) and boys (53.3\%). $5 \%$ of those children born preterm in 2012 , this information matches with the reports of Save the Children and the World Health Organization informing that the rate in Spain was 7.14 out of 100 preterm births in the same year. ${ }^{19}$ Prematurity definition for this study is the considered in the above-mentioned reports, children born before week 37 . The majority of participants are enrolled in public schools $(69.5 \%$ ) compared to $30.5 \%$ of students enrolled privately-owned but partially statefunded schools. It should be noted that $65 \%$ of children are involve in some extra-curricular activities like physical education and $81.4 \%$ of them have siblings.

\section{Instruments}

To determine the psychomotor development of children it was completed the Checklist of Psychomotor Activities (CPA). ${ }^{6}$ The CPA evaluates the following scales and dimensions:

- - The Psychomotor Aspects Scale (PSAS) is composed of five factors or dimensions: laterality (LAT, seven items), dynamic coordination (DC, six items), tonic-postural control (TPC, three items), motor execution (ME, three items), and balance (BAL, five items).

- - The Perceptual-Motor Aspects Scale (PEAS) is composed of five factors or dimensions: respiratory control (RC, three items), body image and body schema (BISC, four items), motor dissociation (MD, three items), visual-motor coordination (VMC, six items), and spatial orientation (SO, two items).

- - The Emotional-Social Aspects Scale (ESAS) is composed of two factors or dimensions: emotional control (EC, six items) and social relationships (SR, five items).

The participants were evaluated by their teachers using the five-level Likert scale where 1 means never and 5 means always. The teachers scored according to the ability of the participants in carry out the task proposed in each item.

The CPA includes the adequate psychometric aspects to be measured resulting in good reliability (Cronbach's alpha) with ranges between .572 for laterality and .872 for balance on the Scale PSAS between .514 (spatial orientation) and .825 (respiratory control) on the PEAS Scale and between .572 (emotional control) and .800 (social relations) on the ESAS scale. The reliability of the scale, which groups all the dimensions, is very high: $0.935 .^{20}$ 


\section{Procedure}

First, some schools in the Province of Albacete-Spain were contacted, the objectives of the study were informed, and their participation was requested. Second, the informed consents were requested to the parents willing to participate, also, the parents answered a questionnaire about the variables of the study, where for example was asked if their child born preterm or full-term. Third, teachers of above-mentioned schools were trained on the usage of the CPA to apply it properly. Fourth, teachers of each course made the evaluation of the children with the help of a member of the study team, within one hour commonly used for physical education. Finally, the data collected from the CPA and the parent's questionnaires were the inputs for the study detailed below.

\section{Method}

A quantitative, non-experimental, descriptive and explanatory, cross-sectional study also known as prospective simple ex-post facto study, was conducted. ${ }^{20}$

The variables used for study are personal characteristics (born preterm or full term and the gender); family members (if is an only child or has siblings) and educational (type of school enrolled in and the performance of extracurricular sports activities).

The result of the analyzed data is divided in two parts: the first part has the description of the ordinal and nominal variables (gender, type of school, extracurricular activities, born preterm or full-term and if there are siblings or is an only child) according to its distribution of frequencies and percentages. The second part has the analysis of the differences between groups carried out by performing the non-parametric Mann-Whitney $\mathrm{U}$ and Kruskal-Wallis tests. It has been decided to use non-parametric statistics because the previous verification of assumptions for the proper use of parametric statistic has indicated the absence of normality for the contrast groups (see Result section) then, the data was transformed and the atypical cases were eliminated, that is, those procedures that did not lead to the verification of the assumption. The software used for the analysis was the SPSS 20 (IBM, 2016).

\section{Results}

\section{Difference between preterm and full-term children}

Table 1 shows the results of the Mann-Whitney $U$ test and the descriptive statistics related to the physical-motor aspects for children born preterm and full-term. 
Table 1

Mann-Whitney test and descriptive statistics for children born preterm and full term - physical-motor skills

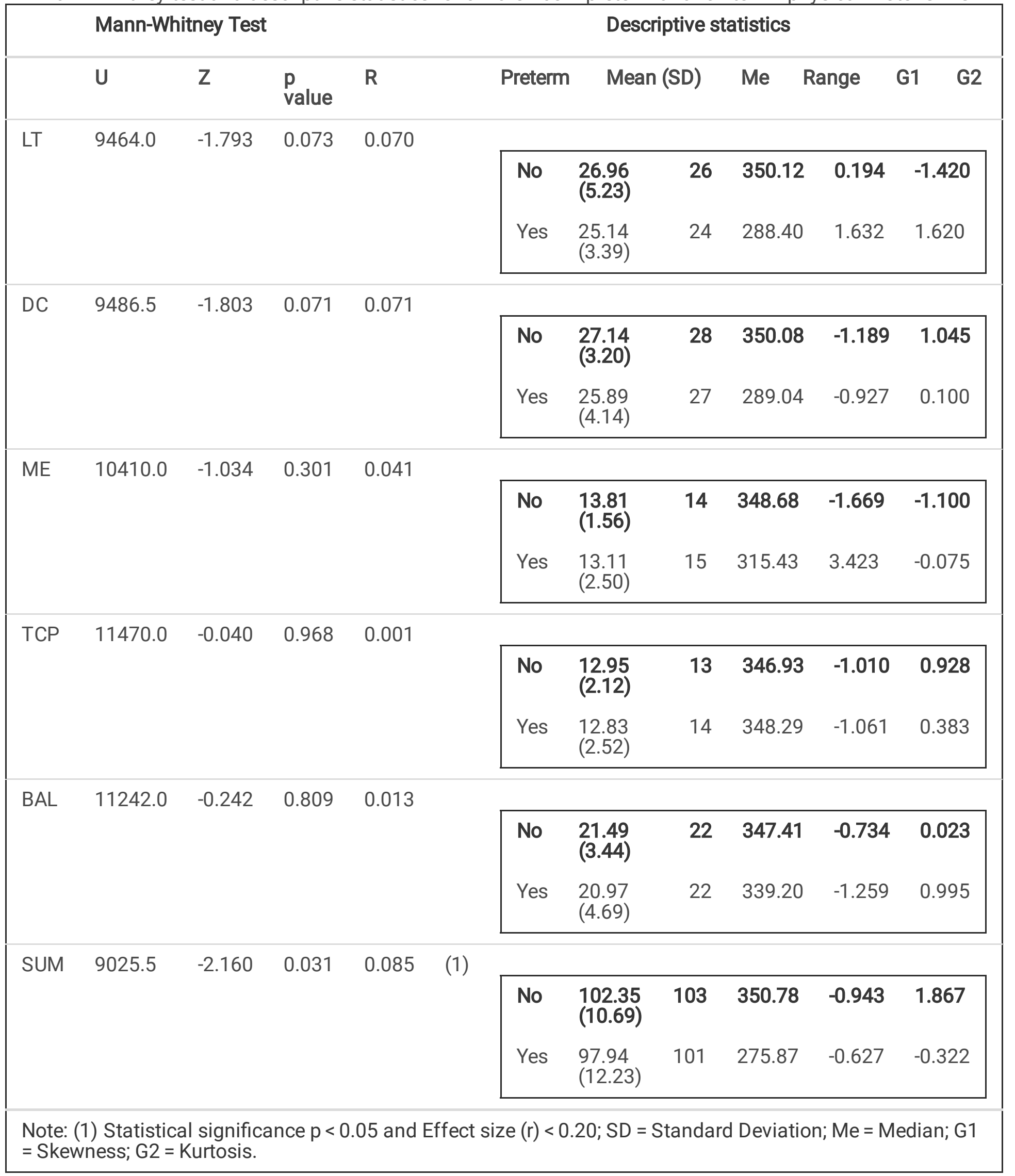

--Insert Table 1 about here-- 
Table 1 shows no significant differences in the variables that describe the physical-motor aspects (laterality, dynamic coordination, motor execution, postural-tonic control and balance) for premature and non-premature children, however, there are differences in the sum of these values (SUM). Based on the median and ranges we can see that premature children have a lower score in the sum of the physical-motor variables. Similarly, the coefficients of skewness (G1) and kurtosis (G2) indicate the non-fulfillment of assumptions of normality in all groups.

- Insert Table 2 about here -- 
Table 2

Mann-Whitney test and descriptive statistics for children born preterm and full term - perceptual-motor skills.

\begin{tabular}{|c|c|c|c|c|c|c|c|c|c|c|c|}
\hline & \multicolumn{6}{|c|}{ Mann-Whitney Test } & \multicolumn{5}{|c|}{ Descriptive statistics } \\
\hline & $\mathbf{U}$ & $\mathbf{Z}$ & $\begin{array}{l}P \\
\text { value }\end{array}$ & $\mathbf{r}$ & & Preterm & Mea & (SD) & Me & Range & G1 \\
\hline \multirow[t]{3}{*}{$\mathrm{RC}$} & 11183.0 & -0.303 & 0.762 & 0.011 & & & & & & & \\
\hline & & & & & & & $\begin{array}{l}13.14 \\
(2.29)\end{array}$ & 14 & 346.50 & -0.627 & -0.322 \\
\hline & & & & & & Yes & $\begin{array}{l}13.00 \\
(2.71)\end{array}$ & 15 & 356.49 & -1.239 & 0.399 \\
\hline \multirow[t]{3}{*}{$\mathrm{BI}$} & 9235.5 & -2.388 & 0.017 & 0.094 & $(1)$ & & & & & & \\
\hline & & & & & & No & $\begin{array}{l}19.04 \\
(2.13)\end{array}$ & 20 & 350.46 & -1.706 & -1.805 \\
\hline & & & & & & Yes & $\begin{array}{l}17.49 \\
(4.09)\end{array}$ & 20 & 281.87 & 14.052 & 2.320 \\
\hline \multirow[t]{3}{*}{ MD } & 9120.5 & -2.210 & 0.027 & 0.087 & $(1)$ & & & & & & \\
\hline & & & & & & No & $\begin{array}{l}13.63 \\
(1.79)\end{array}$ & 14 & 350.64 & -1.732 & 4.075 \\
\hline & & & & & & Yes & $\begin{array}{l}12.31 \\
(3.14)\end{array}$ & 14 & 278.59 & -0.918 & -0.628 \\
\hline \multirow[t]{3}{*}{ VMC } & 8810.0 & -2.360 & 0.018 & 0.092 & $(1)$ & & & & & & \\
\hline & & & & & & No & $\begin{array}{l}26.44 \\
(3.52)\end{array}$ & 27 & 351.11 & -0.908 & -2.902 \\
\hline & & & & & & Yes & $\begin{array}{l}24.29 \\
(5.51)\end{array}$ & 26 & 269.71 & -1.268 & 1.218 \\
\hline \multirow[t]{3}{*}{ so } & 9904.5 & -1.585 & 0.113 & 0.084 & & & & & & & \\
\hline & & & & & & No & $\begin{array}{l}9.29 \\
(1.38)\end{array}$ & 10 & 349.45 & -1.110 & 0.453 \\
\hline & & & & & & Yes & $\begin{array}{l}8.94 \\
(1.34)\end{array}$ & 10 & 300.99 & 0.398 & .778 \\
\hline
\end{tabular}

Note: (1) Statistical significance $p<0.05$ and Effect size $(r)<0.20 ; S D=$ Standard Deviation; Me = Median; G1 = Skewness; $\mathrm{G} 2$ = Kurtosis. 


\begin{tabular}{|c|c|c|c|c|c|c|c|c|c|c|}
\hline \multirow[b]{2}{*}{ SUM } & \multicolumn{4}{|c|}{ Mann-Whitney Test } & \multicolumn{6}{|c|}{ Descriptive statistics } \\
\hline & 9285.0 & -1.931 & 0.053 & 0.076 & & & & & & \\
\hline & & & & & No & $\begin{array}{l}81.53 \\
(8.86)\end{array}$ & 83 & 350.39 & -1.488 & 5.618 \\
\hline & & & & & Yes & $\begin{array}{l}76.03 \\
(14.49)\end{array}$ & 81 & 283.29 & 0.999 & 0.198 \\
\hline
\end{tabular}

Note: (1) Statistical significance $p<0.05$ and Effect size $(r)<0.20 ;$ SD = Standard Deviation; Me = Median; G1 = Skewness; G2 = Kurtosis.

Table 2 shows significant differences between premature and non-premature children related to the body image and body schema, motor dissociation and visual-motor coordination. There are no differences in respiratory control, spatial orientation, or in the sum of perceptual motor variables. Based on the median values and the ranges it is observed that premature children have lower scores on the variables where there are significant differences. Similarly, the coefficients of skewness (G1) and kurtosis (G2) indicate the non-fulfillment of assumptions of normality in all groups.

--- Insert Table 3 about here --

Table 3

Mann-Whitney test and descriptive statistics for children born preterm and full term - socio-relational and affective skills

\begin{tabular}{|c|c|c|c|c|c|c|c|c|c|c|c|}
\hline & \multicolumn{5}{|c|}{ Mann-Whitney Test } & \multicolumn{6}{|c|}{ Descriptive statistics } \\
\hline & $U$ & Z & $\begin{array}{l}\text { valor } \\
\text { p }\end{array}$ & $r$ & Preterm & $\mathrm{Me}$ & & $\mathrm{Me}$ & Inge & G1 & G2 \\
\hline \multirow[t]{3}{*}{ SR } & 10075.5 & -1.259 & 0.208 & .049 & & & & & & & \\
\hline & & & & & No & $\begin{array}{l}20.61 \\
(2.83)\end{array}$ & 21 & 349.19 & -1.244 & 1. & .360 \\
\hline & & & & & Yes & $\begin{array}{l}19.80 \\
(3.49)\end{array}$ & 21 & 305.87 & 0.966 & $0 . \varepsilon$ & .800 \\
\hline \multirow[t]{3}{*}{ SUM } & 8880.5 & -2.289 & 0.022 & $.090 \quad(1)$ & & & & & & & \\
\hline & & & & & No & $\begin{array}{l}46.97 \\
(5.83)\end{array}$ & 48 & 351.00 & -1.244 & 5.2 & .253 \\
\hline & & & & & Yes & $\begin{array}{l}40.75 \\
(8.70)\end{array}$ & 45 & 271.73 & 1.360 & 0.6 & .611 \\
\hline
\end{tabular}

Note: (1) Statistical significance $p<0.05$ and Effect size $(r)<0.20 ; S D=$ Standard Deviation; Me = Median; G1 = Skewness; G2 = Kurtosis. 
Table 3 shows significant differences in emotional control and in the sum of social-emotional aspects since children who are not premature have a higher average range. However, there are no significant differences in social relationships. Again, G1 and G2 values show the coefficients of skewness (G1) and kurtosis (G2), far from the assumptions of normality.

\section{Discussion}

This study evaluated comparatively children born preterm and full-term of five-years-old enrolled in the third level of early childhood school. One of the factors that prevails in this research is that prematurity is a determining factor for the acquisition of motor and emotional skills, this factor may or may not subsequently affect children in the school stage, and that is why we must highlight the following aspects:

Prematurity is a characteristic of children born before 37 weeks of gestation, these children are in a maturation process and this, is interrupted by intrinsic or extrinsic factors inherent in the mother or fetus, this characteristic in several studies shows that preterm children may have lesions at the level of the white matter and/or lack of adequate process of irrigation and oxygenation after the birth, so there are clinical factors that trigger physiological conditions that affect the development of said children, being of high biological risk due to developmental disorders that can trigger. ${ }^{21}$ As shown in the result of the present study, premature children are at a disadvantage when compared with born full-term, this disadvantage is evidenced by a lower score in the sum of the physical-motor variables. In relation to the body image and body schema, motor dissociation, visual-motor coordination, emotional control and social development, this lower score is evidenced in the school age but also it can persist until adulthood. ${ }^{22}$

Premature children present high-risk of develop motor problem, being the characteristic of premature cataloged as an inferred biological risk, this risk refers to those children who, due to pre or post-natal organic causes, may present a transient interference that could affect their development, introducing prematurity as one of these risk causes. ${ }^{23}$ Very premature newborns have a particularly high risk of suffering a significant variety of neurodevelopmental disorders, including cerebral palsy (CP), sensory, cognitive and behavioral disabilities. This is why doctors, teachers and relatives must observe the child in the evolutionary stages, monitoring their motor, socio-emotional and cognitive development.

When children with a possible psychomotor retardation are observed, it is necessary to activate referral mechanisms to provide them with early intervention. Motor development is a set of processes associated with the practice and experiences of the infant. ${ }^{24}$ The child has innate motor skills after birth and as he relates to the context, develops new skills. His goal is to develop continuously skills based on the control of his body, until he can express itself through movement being this a continuous process, unless an alteration occurs. Said alteration will be evident at this stage, when the child face difficulties in developing skills used according to the age of reference. Therefore, it is necessary to highlight the relevance of early intervention programs. ${ }^{25}$ Early childhood education is important in the detection of special educational needs or alterations in the child's development. In most of the cases the teachers are those who detect some of the difficulties in the development of the children by doing a deep assessment in the classroom. ${ }^{26}$

The teacher is who constantly observes children development in the classroom, and it is through this process of observation that some alteration in their development can be identified. In case of observation of alterations in 
the child's development of motor skills, these alterations should be communicated to the psych-pedagogue, who will refer the child and his family to early intervention programs and pediatric centers. Prevention at this age is important since the educational rehabilitation of the alterations is more effective due to the brain plasticity. ${ }^{27}$ Early intervention stimulates the learning processes that will help in the prevention of difficulties and improve the development of children with disabilities or with high risk of having them. ${ }^{28}$ The child must be seen from his individuality and attend to his needs, by accompanying him in his maturity process. The teacher and the pediatrician become observers of this process together with the family, preventing with their practice and actions any difficulties that children may face. ${ }^{29}$ That is why the present study is done completing a checklist where the observer / evaluator is the classroom teacher. The body image and body schema are motor aspects linked to the perception directly related to the emotional development of children and how they interact with their context, other studies indicate that preterm children have a psychomotor development at risk / delayed, and being the motor aspect the most affected that can lead to schooling problems. Factors that in the current study coincide with the above, low scoring for children born preterm.

Deficiency in motor dissociation and visual-motor coordination are closely related to learning disorders, incompetence in perceptual-motor coordination, clumsiness in manual writing (in the first grades) and difficulties in mathematics. ${ }^{30}$

Some studies determine that children born preterm have behavioral and attention problems during psychopathological evaluation. ${ }^{31}$ In the current study, children born preterm show deficiencies in emotional control and in general in all social aspects, which may be related to their motor immaturity and deficiency in body perception. ${ }^{32}$ Premature children suffer various processes at birth depending on their medical condition, the degree of immaturity and early separation by the mother (in short or very long periods), anxiety states may occur.

It should be noted that the main contribution of this study is the identification of the psycho-motor development variables that may be affected in children born preterm when compared to children born full-term at the same age, with the application of the recently developed instrument the CPA. Through the use of the CPA, most of the variables that have been considered in different theoretical models can be evaluated, in addition, being an instrument designed to be used by teachers, it becomes a powerful tool to establish protocols for preventive purposes in children with high motor risk (specifically focused on the variables of visual-motor coordination, motor dissociation and strengthening of the body schema).

It is also essential to strengthen educational programs in the field of emotional control to improve the overall development of children born preterm. In summary, the results of this study allow professionals to design and evaluate the intervention programs aimed to improve procedures for overcome specific deficits identified in children born preterm. ${ }^{33}$ As children improve their CPA results, their performance scores are also expected to improve.

Another important contribution of this study is the provision of psychometric data obtained from children born preterm and full term obtained from the comparative study, as well as the age of the selected sample (five-yearsold), since most of the research conducted were with children at very early ages (between zero and three-yearsold), taking into account the physical-motor aspect and the fact of being healthy children and without severe motor consequences. The aspect measured on this study show how they affect in a lesser or greater degree 
those aspects related to motor perception and the fundamental emotional aspects present in the acquisition and development of the cognitive processes typical of the primary education stage such as the acquisition of basic core subjects, ${ }^{34}$ and the development of socio-emotional elements that evidences their immaturity in relation to their motor perception, as well as the detachment that preterm children face when they are separated from their parents while they are in incubators and the consequences evidenced in the present study, all of them vital factors, highlighting the fact that prevention against this condition or characteristic of born preterm is key. ${ }^{35}$ Indeed, the data presented in this research related to the development of motor skills, in children born preterm educational mediation is matter of prevention since risk factors are present and in most cases consequences can occur if an educational intervention is not carried out.

\section{Conclusions}

- Ethics approval and consent to participate. This study has been performed in accordance with the Declaration of Helsinki and has been approved by the ethics and convivence committee of the CRA Calar del Mundo de Riopár, Albacete, Spain, with reference number 56.

- Consent to publish: Not applicable. This study do not include details, images, or videos relating to an individual person

- Availability of data and materials. Data base available at:

https://unedo365-

my.sharepoint.com/:u:/g/personal/sjromero_psi_uned_es/Ed92yMGQ85FKh8y75I_JfuYBs2aINBBAXJmyA-IIHuihg?e=NORr8Y

- Competing interests: We declare no competing interest

- Funding: This research has not been funded by any public or private institution

- Authors' Contributions:

Pedro Gil Madrona has made substantial contributions to the study including: Conceptualization/design, investigation, supervision and data curation

Sonia Romero Martínez has made substantial contributions to the study including: Methodology, investigation and formal analysis, writing

Caren Roz Faraco has made substancial contributions to the study including: conceptualization/design and writing

- Acknowledgements

To the participating schools in Albacete, Spain.

\section{Abbreviations}

\section{BAL}

Balance

BISC 
Body Image and Body Schema

CPA

Checklist of Psychomotor Activities

DC

Dynamic Coordination

EC

Emotional Control

\section{ESAS}

Emotional-Social Aspects Scale

\section{LAT}

Laterality

LBW

Low Birth Weight

MD

Motor Dissociation

ME

Motor Execution

\section{PEAS}

Perceptual-Motor Aspects Scale

\section{PSAS}

Psychomotor Aspects Scale

RC

Respiratory Control

so

Spatial Orientation

SR

Social Relationships

TPC

Tonic-Postural Control

VMC

Visual-Motor Coordination

\section{Declarations}

\section{- Ethics approval and consent to participate.}

- This study has been performed in accordance with the Declaration of Helsinki and has been approved by the ethics and convivence committee of the CRA Calar del Mundo de Riopár, Albacete, Spain, with reference number 56.

- Consent to publish:

- Not applicable. This study do not include details, images, or videos relating to an individual person 


\section{- Availability of data and materials.}

- Data base available at:

\section{- Competing interests:}

- We declare no competing interest

\section{- Funding:}

This research has not been funded by any public or private institution

\section{- Authors' Contributions:}

Pedro Gil Madrona has made substantial contributions to the study including: Conceptualization/design, investigation, supervision and data curation

\section{- Acknowledgements}

To the participating schools in Albacete, Spain.

\section{References}

1. Roz-Faraco CC, Pascual-Gomez I. Application of an Observation System in the Practice of Psychomotor Circuits in Early Education. Revista de Cercetare si Interventie Sociala. 2019;66:315-27.

DOI:10.33788/rcis.66.18.

2. Foulder-Hughes $L$, Cooke R. Motor, cognitive, and behavioural disorders in children born very preterm. Dev Med Child Neurol. 2003;45(2):97-103. doi:10.1017/S0012162203000197.

3. Gil-Madrona P, Contreras OR, Roblizo MJ, Gómez I. Potencial pedagógico de la Educación Física en la Educación Infantil: atributos y convicciones. Infancia y aprendizaje. 2008;31(2):165-78.

4. Marret S, Marchand-Martin L, Picaud JC, Hascoët JM, Arnaud C, Rozé JC, et al. Lesión cerebral en niños muy prematuros y discapacidades neurosensoriales y cognitivas durante la infancia: el estudio de cohorte EPIPAGE. PLoS ONE. 2013;8(5):e62683.

5. Bourke J, Wong K, Srinivasjois R, Pereira G, Shepherd CC, White SW. \& Leonard H. Predicting Long-Term Survival Without Major Disability for Infants Born Preterm. J Pediatr. 2019;215:90-7.

6. Romero-Martínez SJ, Ordóñez-Camacho XG, Gil-Madrona P. Development of the Checklist of Psychomotor Activities for 5-to 6-Year-Old Children. Percept Mot Ski. 2018;125(6):1070-92.

7. Malatesta CZ, Culver C, Tesman JR, Shepard B, Fogel A, Reimers M, Zivin G. The development of emotion expression during the first two years of life. Monogr Soc Res Child Dev. 1989: 123-136.

8. Spittle AJ, Orton J. Cerebral palsy and developmental coordination disorder in children born preterm. In: Seminars in Fetal and Neonatal Medicine. 2014, 19(2): 84-89. 
9. Sánchez-Caravaca J. Atención Temprana y Niños Prematuros. Madrid -España: EAE; 2011.

10. Torrioli MG, Frisone MF, Bonvini L, Luciano R, Pasca MG, Lepori R,... \& Guzzetta F. Perceptual-motor, visual and cognitive ability in very low birthweight preschool children without neonatal ultrasound abnormalities. Brain Dev. 2000;22(3):163-8.

11. Blencowe H, Cousens S, Oestergaard M, Chou D, Moller AB, Narwal R, Adler A, Garcia CV, Rohde S, Say L, Lawn JE. National, regional and worldwide estimates of preterm birth. The Lancet. 2012;379(9832):216272.

12. Piek JP, Dawson L, Smith LM, Gasson N. The role of early fine and gross motor development on later motor and cognitive ability. Hum Mov Sci. 2008;27(5):668-81.

13. De Kieviet JF, Piek JP, Aarnoudse-Moens CS, Oosterlaan J. Motor development in very preterm and very lowbirth-weight children from birth to adolescence: a meta-analysis. JAMA New Open. 2009;302(20):2235-42.

14. Gil-Madrona P, Romero-Martínez SJ, Sáez-Gallego NM, Ordóñez-Camacho XG. Psychomotor Limitations of Overweight and Obese Five-Year-Old Children: Influence of Body Mass Indices on Motor, Perceptual, and Social-Emotional Skills. Int J Environ Res Public Health. 2019;16(3):427-47.

doi.org/10.3390/ijerph16030427.

15. Spittle AJ, Anderson PJ, Lee KJ, Ferretti C, Eeles A, Orton J, ... Doyle LW. Preventive care at home for very preterm infants improves infant and caregiver outcomes at 2 years. Pediatrics. 2010;126(1):71-8.

16. Sailer U, Flanagan JR, Johansson RS. Eye-hand coordination during learning of a novel visomotor task. J Neurosci. 2005;25(39):8833-42.

17. Albacete City Council. Public and Private Schools in the Province of Albacete. Available online: http://www.albacete.es/es/webs-municipales/educacion/primaria-y-secundaria/colegios-publicosyconcertados (accessed on 17 July 2017).

18. World Medical Association. World Medical Association Declaration of Helsinki:Ethical principles for medical research involving human subjects. JAMA New Open. 2013;310(20):2191-4.

doi:10.1001/jama.2013.281053.

19. Save the Children \& World Health Organization. Resumen ejecutivo de Nacidos Demasiado Pronto: Informe de Acción Global sobre Nacimientos Prematuros 2012; March of Dimes, PMNCH.

20. Montero I, León OG. A guide for naming research studies in Psychology. Int J Clin Health Psychol. 2007;7:847-62.

21. Blauw-Hospers $\mathrm{CH}$, de Graaf-Peters VB, Dirks T, Bos AF, Hadders-Algra M. Does early intervention in infants at high risk for a developmental motor disorder improve motor and cognitive development? Neurosci Biobehav Rev. 2007;31(8):1201-12.

22. Marlow N. Neurocognitive outcome after very preterm birth Archives of Disease in Childhood Fetal and Neonatal Edition. 2004; 89, pp. F224-F228.

23. Wolke D, Samara M, Bracewell M, Marlow N, EPICure Study Group. Specific language difficulties and school achievement in children born at 25 weeks of gestation or less. Arch Dis Child. 2008;152(2):256-62.

24. López de la Fuente M. Teorías del control motor, principios de aprendizaje motor y concepto Bobath. Revista TOG. 2013;10:1-27.

25. Williams J, Holmes CA. Improving the early detection of children with subtle developmental problems. J Child Health Care. 2004;8(1):34-46. 
26. Fernández JM. Atención a la Diversidad en el Aula de Educación Infantil. Paraninfo: Madrid; 2015.

27. Spittle A, Orton J, Anderson PJ, Boyd R, Doyle LW. Early developmental intervention programmes provided post hospital discharge to prevent motor and cognitive impairment in preterm infants. Cochrane database of systematic reviews. 11;2015.

28. Arbones-Fernández B. Detección, prevención y tratamiento de dificultades del aprendizaje. Como descubrir, tratar y prevenir los problemas en la escuela. Gesgiblo: Vigo; 2005.

29. Severson HH, Walker HM, Hope-Doolittle J, Kratochwill TR, Gresham FM. Proactive, early screening to detect behaviorally at-risk students: Issues, approaches, emerging innovations, and professional practices. J Sch Psychol. 2007;45(2):193-223.

30. Smits-Engelsman BCM, Wilson PH, Westenberg Y, Duysens J. Fine motor deficiencies in children with developmental coordination disorder and learning disabilities: An underlying open-loop control deficit. Hum Mov Sci. 2003;22(4-5):495-513.

31. Bermúdez OG, Quintana FC, de los Ángeles Sosa M, de la Cruz J, Mañas M, García MP. Alteraciones neuropsicológicas y emocionales en niños prematuros de muy bajo peso al nacer. Revista Argentina de Ciencias del Comportamiento. 2012;4(2):3-10.

32. Piek JP, Dyck MJ. Sensory-motor deficits in children with developmental coordination disorder, attention deficit hyperactivity disorder and autistic disorder. Hum Mov Sci. 2004;23(3-4):475-88.

33. Schonhaut L, Armijo I, Schönstedt M, Alvarez J, Cordero M. Validity of the ages and stages questionnaires in term and preterm infants. Pediatrics. 2013;131(5):e1468-74.

34. Pritchard VE, Clark CA, Liberty K, Champion PR, Wilson K, Woodward LJ. Early school-based learning difficulties in children born very preterm. Early Hum Dev. 2009;85(4):215-24.

35. Ishizaki Y, Nagahama T, Kaneko K. Mental health of mothers and their premature infants for the prevention of child abuse and maltreatment. Health. 2013;5(03):612-5.

\section{Supplementary Files}

This is a list of supplementary files associated with this preprint. Click to download.

- STROBEStatement.docx 